\title{
Cerebrospinal Fluid IL-21 Levels in Neuromyelitis Optica and Multiple Sclerosis
}

\author{
Aimin Wu, Xiaonan Zhong, Honghao Wang, Wen Xu, Chen Cheng, \\ Yongqiang Dai, Jian Bao, Wei Qiu, Zhengqi Lu, Xueqiang Hu
}

\begin{abstract}
Background: Neuromyelitis optica (NMO) and multiple sclerosis (MS) are inflammatory demyelinating diseases of human central nervous system (CNS) with complex pathogenesis. IL-21/IL-21R regulates activation, proliferation and survival of both $\mathrm{T}$ cells and B cells, which are involved in the pathogenesis of NMO and MS. High levels of serum IL-21 were observed in NMO patients. However, concentration of cerebrospinal fluid (CSF) IL-21 in MS and NMO patients still remain unknown. Object: To detect the CSF concentration of IL-21 in NMO and MS patients and to evaluate its relationship with disease activity, particularly concerned about its impact on humoral immunity. Methods: CSF IL-21 was detected by an enzyme-linked immunosorbent assay (ELISA) in NMO patients $(n=21)$, MS patients $(n=20)$ and controls $(n=16)$. Results: CSF concentration of the IL-21 was noticeably elevated in NMO $(p=0.012)$ and borderline significantly increased in MS $(p=0.115)$. In addition, this occurrence was associated with humoral immune activity as shown by a correlation between IL-21 and complement in NMO cohort $(p=0.023)$ and high IL-21 levels in autoantibodypositive subgroup $(p=0.027)$. Conclusions: The concentration of CSF IL-21 was noticeably elevated and might have a positive correlation with humoral immune activity in NMO.
\end{abstract}

RÉSUMÉ: Les niveaux d'IL-21 du liquide céphalo-rachidien dans la neuromyélite optique et la sclérose en plaques. Contexte : La neuromyélite optique (NMO) et la sclérose en plaques (SP) sont des maladies démyélinisantes inflammatoires du système nerveux central (SNC) humain dont la pathogenèse est complexe. IL-21/IL-21R régule l'activation, la prolifération et la survie des cellules T et des cellules $\mathrm{B}$ qui sont impliquées dans la pathogenèse de la NMO et de la SP. Des taux sériques élevés d'IL-21 ont été observés chez des patients atteints de NMO. Cependant, la concentration d'IL-21 dans le liquide céphalo-rachidien (LCR) de patients atteints de SP ou de NMO demeure inconnue. Objectif: Le but de l'étude était de déterminer la concentration d'IL-21 dans le LCR de patients atteints de NMO ou de SP et d'évaluer sa relation à l'activité de la maladie, particulièrement en ce qui a trait à son impact sur l'activité immunitaire humorale. Méthode : L'IL-21 dans le LCR a été identifié par ELISA chez 21 patients atteints de NMO, 20 patients atteints de SP et 16 sujets témoins. Résultats : La concentration d'IL-21 dans le LCR était sensiblement élevée chez les patients atteints de NMO $(\mathrm{p}=0,012)$ et limite chez les patients atteints de SP $(\mathrm{p}=0,115)$. De plus, ceci était associé à une activité immunitaire humorale comme le démontre la corrélation entre IL-21 et le complément dans la cohorte de patients atteints de NMO ( $p=0,023)$ et un niveau élevé d'IL-21 dans le sous-groupe de patients possédant des autoanticorps $(\mathrm{p}=0,027)$. Conclusions : La concentration d'IL-21 dans le LCR était sensiblement élevée chez les patients atteints de NMO et pourrait avoir une corrélation positive avec l'activité immunitaire humorale.

Can J Neurol Sci. 2012; 39: 813-820

Neuromyelitis optica (NMO) and Multiple sclerosis (MS) are two typical inflammatory demyelinating diseases of the central nervous system (CNS) with complex pathogenesis, and they share many similarities. Neuromyelitis optica was considered an optic-spinal form of MS until specific antibodies (NMO-IgG) were suggested to be a biomarker of NMO, distinguishing it from conventional MS ${ }^{1}$. T cells have emerged as a key player in the pathogenesis of $\mathrm{MS}^{2}$. We also found increased levels of $\mathrm{CD}^{+} \mathrm{T}$ cells in NMO patients ${ }^{3}$. Simultaneously, B cells are believed to play an important role in the pathogenesis of these diseases. A role of B cells in MS pathogenesis has been suggested by the presence of oligoclonal immunoglobulin bands $(\mathrm{OCBs})$ in cerebrospinal fluid $(\mathrm{CSF})^{4,5}$. In addition, NMO-IgG is compelling evidence for $\mathrm{B}$ cells involvement in NMO pathogenesis $^{6}$. Moreover, therapies which eliminate antibodies (plasma exchange ${ }^{7}$, intravenous gamma globulin ${ }^{8}$ ), or which target B cells (anti-CD20 antibodies) ${ }^{9-11}$ are effective in NMO patients.

The cellular interactions that constitute a functional immune system require a communication network that includes cytokines and cytokine receptors. In 2000, a new type 1 cytokine receptor

From the Department of Neurology, the Third Affiliated Hospital of Sun Yat-sen University, Guangzhou, Guangdong Province, China.

Received April 2, 2012. Final Revisions Submitted June 26, 2012.

Correspondence to: Xueqiang Hu, Multiple Sclerosis Center, Department of

Neurology, The Third Affiliated Hospital of Sun yat-sen University, No. 600

Tianhe Road, Guangzhou 510630, Guangdong Province, China.

Email: huxueqiangzssy@yahoo.com.cn. 
was discovered ${ }^{12}$. Soon after, a functional cloning approach identified a four-helix-bundle cytokine with structural relation to interleukin (IL)-2, IL-4 and IL-15 as the natural ligand to this receptor, naming the new entities IL- $21^{13}$. The IL-21 receptor (IL-21R) is widely expressed, indicating a broad range of actions of IL-21 $1^{14,15}$. IL-21/IL-21R regulates activation, proliferation and survival of both $\mathrm{CD}^{+} \mathrm{T}$ cells and $\mathrm{B}$ cells, and limits the differentiation of inducible Tregs and counteracts their suppressive properties on effector $\mathrm{T}$ cells ${ }^{16}$, both of which are involved in the pathogenesis of NMO and MS. IL-21 now has also been reported to contribute to the development of Th17 cells, and Th17 cells can produce IL-21, acting in an autocrine manner to amplify its own synthesis. Moreover, IL-21 also inhibits the development of Treg, which can suppress autoimmune responses in NMO and $\mathrm{MS}^{17,18}$. Most importantly, IL-21 is recognized as "An Executor of B Cell Fate"19: Depending on the interplay with costimulatory signals and on the developmental stage of a B cell, IL-21 can induce B cell proliferation, differentiation into Ig-producing plasma cells, or apoptosis. Alone and in combination with Th cell-derived cytokines IL-21 can regulate class switch recombination to IgG, $\operatorname{Ig} \mathrm{A}$, or $\operatorname{IgE}$ isotypes, indicating its important role in shaping the effector function of B cells. ${ }^{20,21}$

In our previous studies, high serum IL-21 concentration was observed in NMO, and serum IL-21 seemed to be elevated in MS cohort; thought did not quite reach statistical significance. ${ }^{22}$ However, levels of CSF IL-21 in NMO and MS patients still remain unknown. The aim of the present study was to detect the CSF concentration of pleiotropic cytokine IL-21 in NMO and MS patients and to evaluate its relationship with disease activity, particularly its impact on humoral immunity.

\section{SubJeCts AND Methods}

\section{Patients and controls}

Twenty-one NMO patients, based on the 2006 Wingerchuk diagnostic criteria, ${ }^{23}$ and 20 relapsing-remitting MS (RRMS) patients fulfilling 2010 McDonald's diagnostic criteria ${ }^{24}$ from Demyelinating Disease Database of the Neurology Department of the Third Affiliated Hospital of Sun Yat-sen University were enrolled. Patients enrolled from the database were diagnosed by two specialized neurologists. Serum NMO-IgG was detected using indirect immunofluorescence kits (EUROIMMUN Medizinische Labordiagnostika, Lübeck, Germany) according to the manufacturer's instructions. Each sample was assayed at least twice, by two examiners blind to the origin of the specimen. Samples that gave a positive result twice were deemed to be positive. Only NMO-IgG seropositive NMO patients were enrolled and all MS patients were NMO-IgG negative. Written informed consent was obtained from each participant. A clinical relapse was defined as a sudden appearance of new symptoms, lasting for at least 24 hours (h), with an increase of Expanded Disability Status Scale (EDSS) over 1.0 before sampling. All samples were taken during relapse phase before treatment. Patients were not receiving immunomodulatory therapies during remission. Sixteen controls with noninflammatory neurological diseases (amyotrophic lateral sclerosis, $n=4$; multiple system atrophy, $n=1$; cervical spondylosis, $n=6$; sciatica, $n=3$; tension type headache, $n=2$ ) were recruited. Demographic and clinical features of the patients are shown in Table 1. There was no significant difference in age and gender between the groups.

Table 1: Demographic and clinical features of the patients and controls

\begin{tabular}{llll}
\hline & NMO & MS & controls \\
\hline No. of subjects, $\mathrm{n}$ & 21 & 20 & 16 \\
Gender, female/male & $16 / 5$ & $13 / 7$ & $9 / 7$ \\
Age(years) & $34.0(11-61)$ & $35.5(14-52)$ & $34.5(11-70)$ \\
Onset age(years) & $32.0(7-59)$ & $32.0(12-48)$ & N/A \\
Disease duration(years) & $3.0(2-14)$ & $3.5(2-8)$ & N/A \\
EDSS & $4.0(1.0-8.0)$ & $2.3(1.0-9.5)$ & N/A \\
ARR & $1.00(0.40-2.00)$ & $0.59(0.25-1.00)$ & N/A \\
\hline
\end{tabular}

Age (years) refers to age at sampling time point. Disease duration (years) refers to years from disease onset to sampling. ARR: annualized relapse rate; EDSS, Expanded Disability Status Scale; MS, multiple Sclerosis; N/A: not available; NMO, Neuromyelitis optica.

\section{Study of CSF samples}

Cerebrospinal fluid was collected by lumbar puncture performed for diagnostic purposes. The CSF white blood cell counting (WBC), total protein concentration (TP), glucose (GLU), chloride (CL) and IgG index were detected by hospital laboratories of the Third Affiliated Hospital of Sun Yat-sen University.

\section{CSF IL-21 Enzyme-linked immunosorbent assay (ELISA)}

Cerebrospinal fluid used for research purposes was centrifuged immediately after sampling to isolate the cells and larger particles, then was stored frozen at $-80^{\circ} \mathrm{C}$ until analysis. CSF IL-21 levels were measured using commercially available ELISA kits (Bender Med Systems, Vienna, Austria) according to the manufacturer's instructions. The minimal detectable dose of IL-21 was $20.0 \mathrm{pg} / \mathrm{ml}$. Goodness of fit for a representative standard curve was $r^{2}=0.999$. Measurements were performed in duplicates using $50 \mu \mathrm{l}$ undiluted cell-free CSF.

\section{Serological Testing}

Blood samples were collected during relapse phase before treatment. After sampling, samples were immediately sent to hospital laboratories of the Third Affiliated Hospital of Sun Yatsen University, where complement (C3, C4 and CH50) and rheumatic autoantibodies (antinuclear antibodies (ANA); and extractable nuclear antigens (ENA), including Anti-RNP, anti- 
SM, anti-Ro/SSA, anti-La/SSB, anti-JO-1, anti-SCL-70 and antiribosomal $\mathrm{P}$ protein antibodies) were detected.

\section{Statistical analysis}

The data were presented as mean \pm standard deviation (CSF IL-21, WBC, TP, GLU and CL levels, IgG index and complement) or median with range (age, onset age, disease duration, annual relapse rate (ARR), and EDSS score). Differences between different subgroups were analyzed using Mann-Whitney U test. Correlations between IL-21 and clinical activity, CSF routine (CSF WBC, TP, GLU and CL), IgG index, complement were analyzed using Spearman's rank test. $P$ value $<0.05$ was considered statistically significant. All statistical analysis was performed using SPSS 16.0 (SPSS Inc, Chicago, IL, USA) for Windows.

\section{RESULT}

\section{CSF IL-21 levels in NMO and MS}

The concentration of IL-21 was detected in cell-free CSF from NMO patients $(n=21)$, MS $(n=20)$ patients and controls $(\mathrm{n}=16)$ using ELISA. Mean IL-21 (pg/ml) was $99.95 \pm 31.98$ for NMO and $93.45 \pm 43.17$ for MS, compared to $71.18 \pm 32.68$ for the controls. IL-21 levels were dramatically higher in NMO cohort than the controls ( $\mathrm{p}=0.012)$. IL-21 concentration seemed to be elevated in MS cohort, thought did not quite reach statistical significance $(p=0.115)$. When comparing IL-21 levels within subgroups of

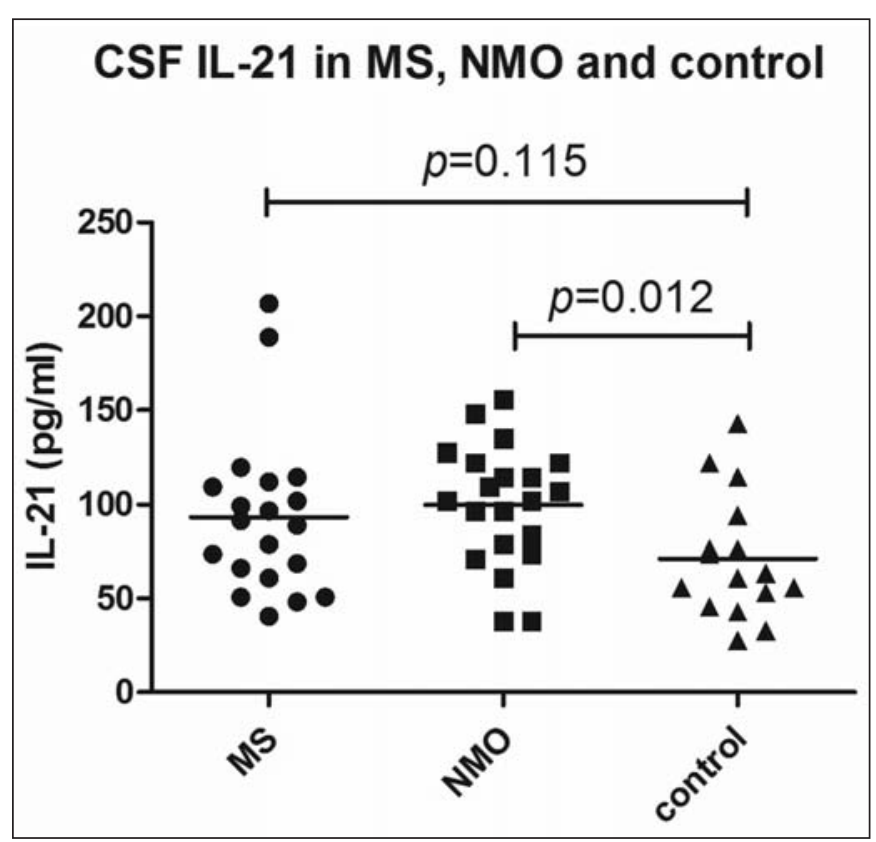

Figure 1: IL-21 levels were higher in NMO cohort than the controls $(p=0.012)$, and seemed to be elevated in MS cohort (MS, $p=0.115)$. No notable difference was found between NMO and MS $(p=0.230)$.

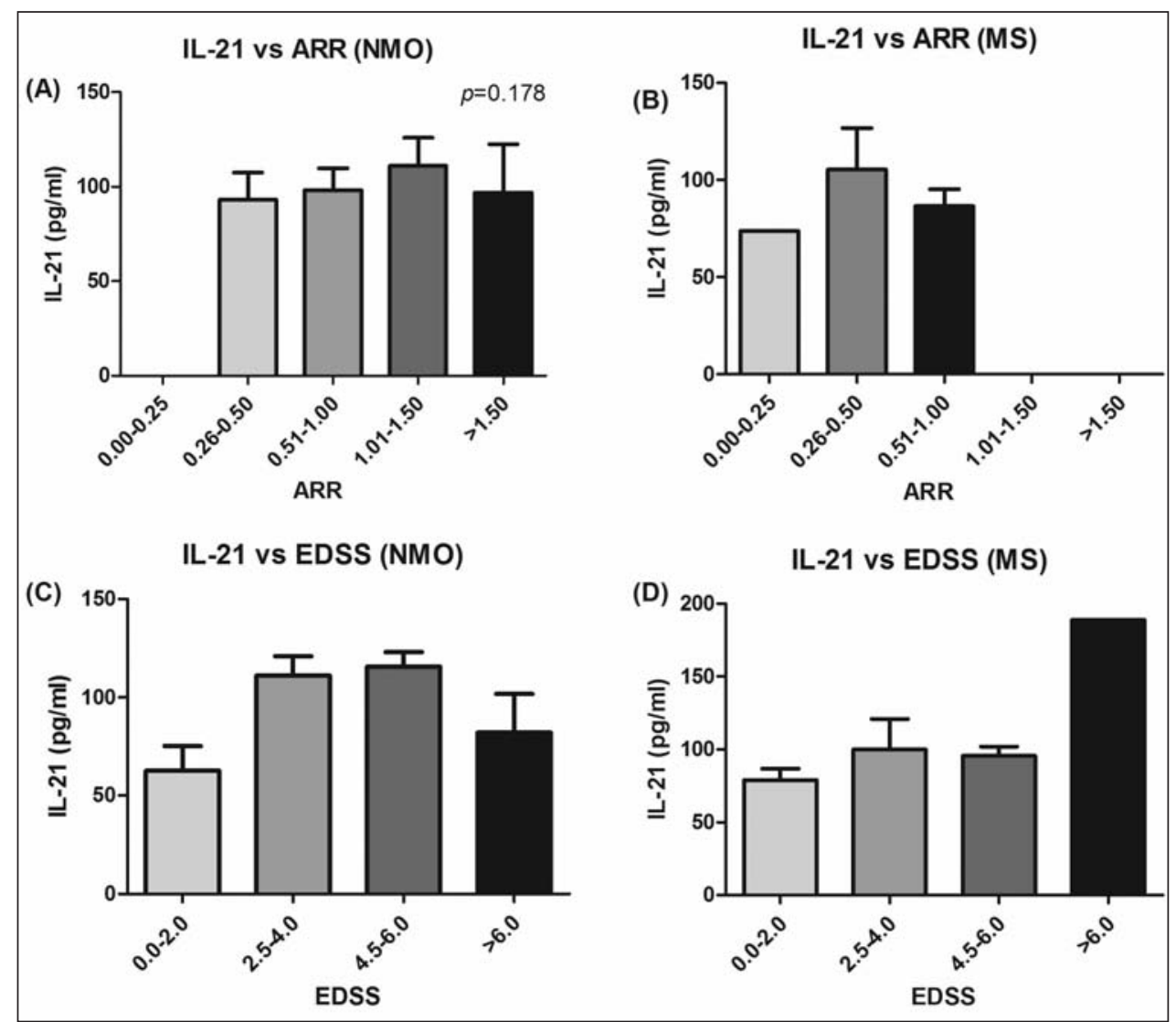

Figure 2: (A) Patients with higher relapse rate exhibited higher IL-21 concentration in their CSF in NMO cohort (NMO, $p=0.178)$. (B) CSF IL21 concentration in MS cohort did not show any correlation with ARR (MS, $p=0.889)$. (C,D) No correlation between levels of IL-21 and EDSS score was found in NMO $(p=0.741)$ and MS patients $(p=0.319)$. 


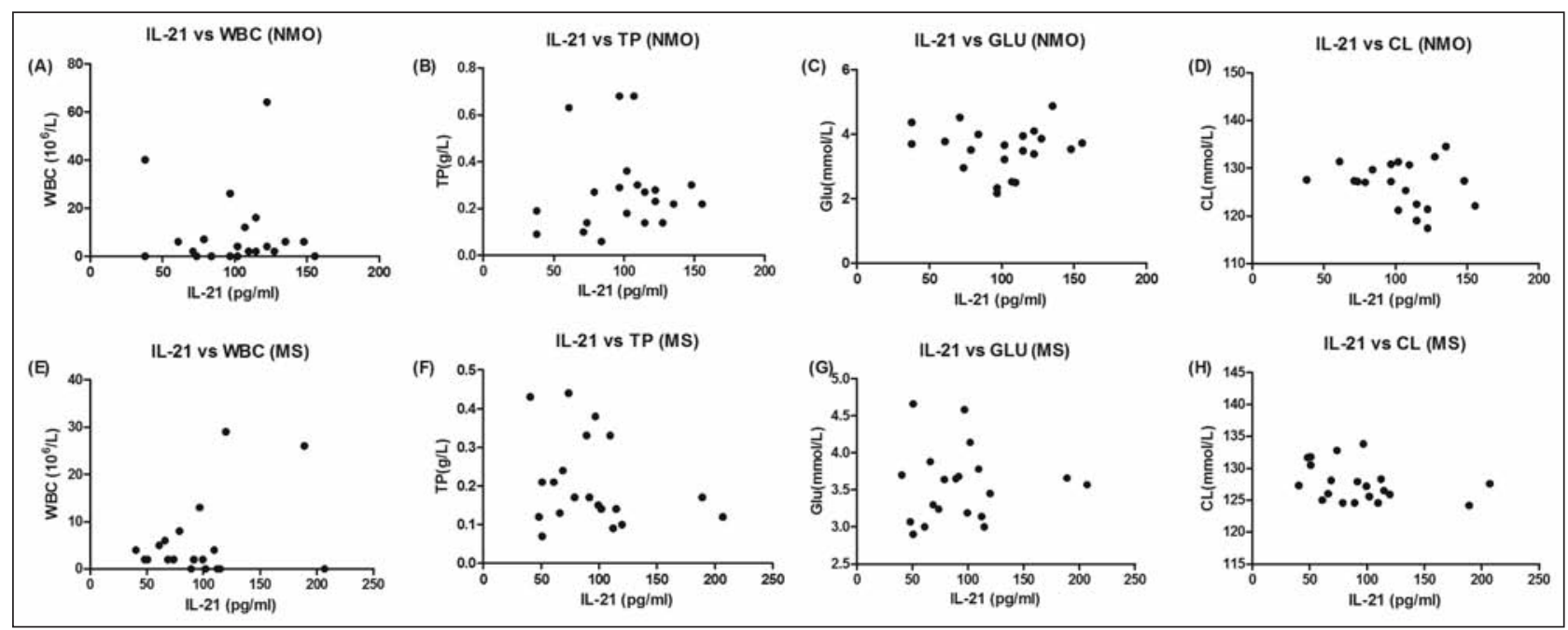

Figure 3: IL-21 concentration did not associate with CSF WBC or TP in NMO and MS subgroups (NMO: WBC, $p=0.713, T P, p=0.425 ;$ MS: WBC, $p=0.673, T P, p=0.261$ ). In both cohorts, no correlation between levels of IL-21 and GLU or CL was observed.

inflammatory demyelinating disease, no notable difference was found between NMO and MS ( $p=0.230)$. (Figure 1)

\section{CSF IL-21 and clinical activity}

Correlations between IL-21 and clinical activity, CSF routine, IgG index, complement were shown in Table 2. Clinical data including ARR and EDSS scores of all 21 NMO patients and 20 MS patients were reviewed. The median ARR (/year) was 1.00 $(0.40-2.00)$ in NMO and $0.59(0.25-1.00)$ in MS cohort.
Neuromyelitis optica patients relapsed more frequently $(p=0.008)$. Patients with higher relapse rate exhibited higher IL21 concentration in their CSF in NMO cohort, but this trend was not statistically significant ( $p=0.178$ ). Cerebrospinal fluid IL-21 concentration in MS subgroup did not show any correlation with ARR $(p=0.889)$. (Figure 2A, B) For NMO patients, the EDSS score was 4.0 (1.0-8.0), and for MS patients was 2.3 (1.0-9.5). NMO cohort had more severe disease disability $(p=0.002)$. No correlation between CSF IL-21 and EDSS score was found in NMO $(p=0.741)$ and MS $(p=0.319)$. (Figure 2C, D)

Table 2: Correlation between CSF IL-21 and clinical activity, CSF routine, IgG index, complement

\begin{tabular}{|c|c|c|c|c|}
\hline Correlation & $\begin{array}{l}\mathrm{NMO} \\
\mathrm{R} \text { value }\end{array}$ & $\mathrm{P}$ value & $\begin{array}{l}\mathrm{MS} \\
\mathrm{R} \text { value }\end{array}$ & $P$ value \\
\hline \multicolumn{5}{|l|}{ clinical activity } \\
\hline IL-21 and ARR & 0.305 & 0.178 & -0.033 & 0.889 \\
\hline IL-21 and EDSS & 0.077 & 0.741 & 0.235 & 0.319 \\
\hline \multicolumn{5}{|l|}{ CSF routine } \\
\hline IL-21 and CSF WBC & 0.085 & 0.713 & -0.101 & 0.673 \\
\hline IL-21 and CSF TP & 0.184 & 0.425 & -0.264 & 0.261 \\
\hline IL-21 and CSF GLU & 0.025 & 0.915 & 0.031 & 0.897 \\
\hline IL-21 and CSF CL & -0.217 & 0.345 & -0.363 & 0.116 \\
\hline IL-21 and IgG index & 0.209 & 0.589 & 0.703 & $0.078^{*}$ \\
\hline \multicolumn{5}{|l|}{ complement } \\
\hline IL-21 and C3 & 0.340 & 0.154 & 0.113 & 0.676 \\
\hline IL-21 and C4 & -0.150 & 0.540 & -0.403 & 0.122 \\
\hline IL-21 and CH50 & 0.518 & $0.023 * *$ & -0.125 & 0.644 \\
\hline
\end{tabular}

$* \mathrm{P}<0.10$; ** $\mathrm{P}<0.05$; ARR: annualized relapse rate; $\mathrm{CL}$, chloride ions; CSF, cerebrospinal fluid; EDSS, Expanded Disability Status Scale; IL-21, interleukin-21; GLU, glucose; MS, multiple sclerosis; NMO, neuromyelitis optica; TP, total protein; WBC, white blood cells. 


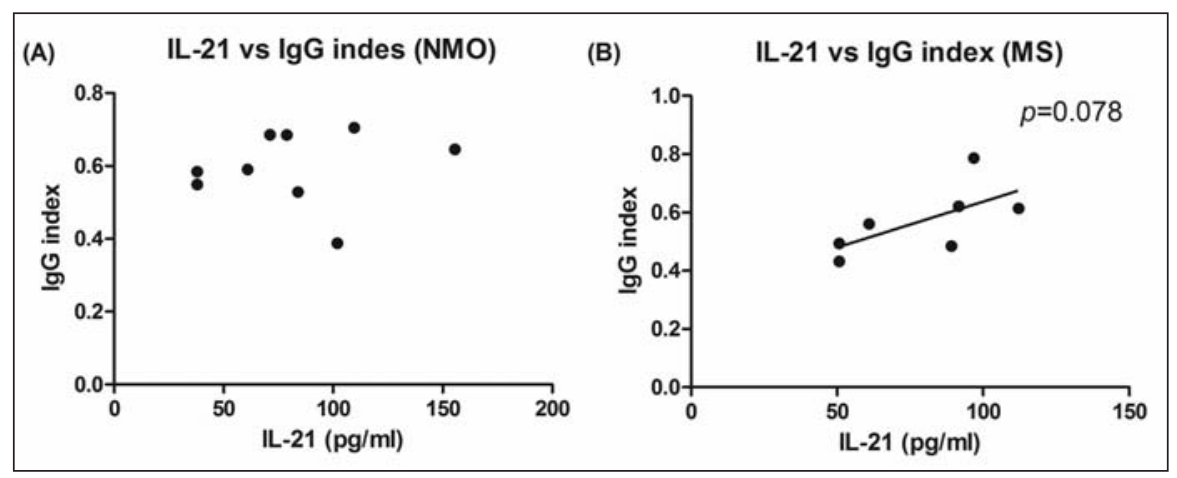

Figure 4: Lack of correlation between IL-21 and IgG index was found in NMO (NMO, $p=0.589)$. MS subgroup revealed a trend to an increased IgG index with increased CSF IL-21 (MS, p=0.078).

\section{CSF IL-21 and CSF routine}

Cerebrospinal fluid routine was detected in all patients and controls. Mean CSF WBC $\left(10^{6} / \mathrm{L}\right)$ of NMO patients was $9.48 \pm 15.96$ and the level was $5.45 \pm 8.20$ in MS subgroup, and $3.28 \pm 2.70$ in control group. Mean CSF TP $(\mathrm{g} / \mathrm{L})$ was $0.27 \pm 0.18$ for NMO, $0.21 \pm 0.11$ for MS and $0.15 \pm 0.06$ for the controls. CSF TP was increased significantly in NMO cohorts $(p=0.006)$. IL-21 concentration did not associate with CSF WBC or TP in NMO and MS (NMO: WBC, $p=0.713$, TP, $p=0.425$; MS: WBC, $p=0.673$, TP, $p=0.261$ ). Similarly, no correlation between levels of IL-21 and GLU or CL was observed in both cohorts (Figure 3).

\section{CSF IL-21 and IgG index}

$\mathrm{IgG}$ index was detected in nine NMO patients and seven MS patients. Neuromyelitis optica patients had a mean IgG index of
$0.60 \pm 0.10$, and MS patients had a mean of $0.57 \pm 0.12$, comparing to $0.39 \pm 0.07$ in the controls. IgG index was elevated in demyelinating disease (NMO vs controls, $p=0.009$; MS vs controls, $p=0.023$ ). Lack of correlation between IL-21 and IgG index was found in NMO $(p=0.589)$. The MS subgroup revealed a trend to an increased IgG index with increased CSF IL-21 $(p=0.078)$. (Figure 4)

\section{CSF IL-21 and complement}

Complement was detected in 19 NMO patients, 16 MS patients and 8 controls. Mean C $3(\mathrm{~g} / \mathrm{L})$ was $1.22 \pm 0.24$ for NMO and $1.17 \pm 0.23$ for MS, compared to $1.15 \pm 0.26$ for the controls. NMO patients had a mean $\mathrm{C} 4(\mathrm{~g} / \mathrm{L})$ of $0.20 \pm 0.11$, and mean $\mathrm{C} 4$ was $0.21 \pm 0.09$ in MS, and was $0.15 \pm 0.06$ in the controls. Mean CH50 (U/ml) was $48.21 \pm 10.55$ in $\mathrm{NMO}, 47.56 \pm 6.90$ in MS

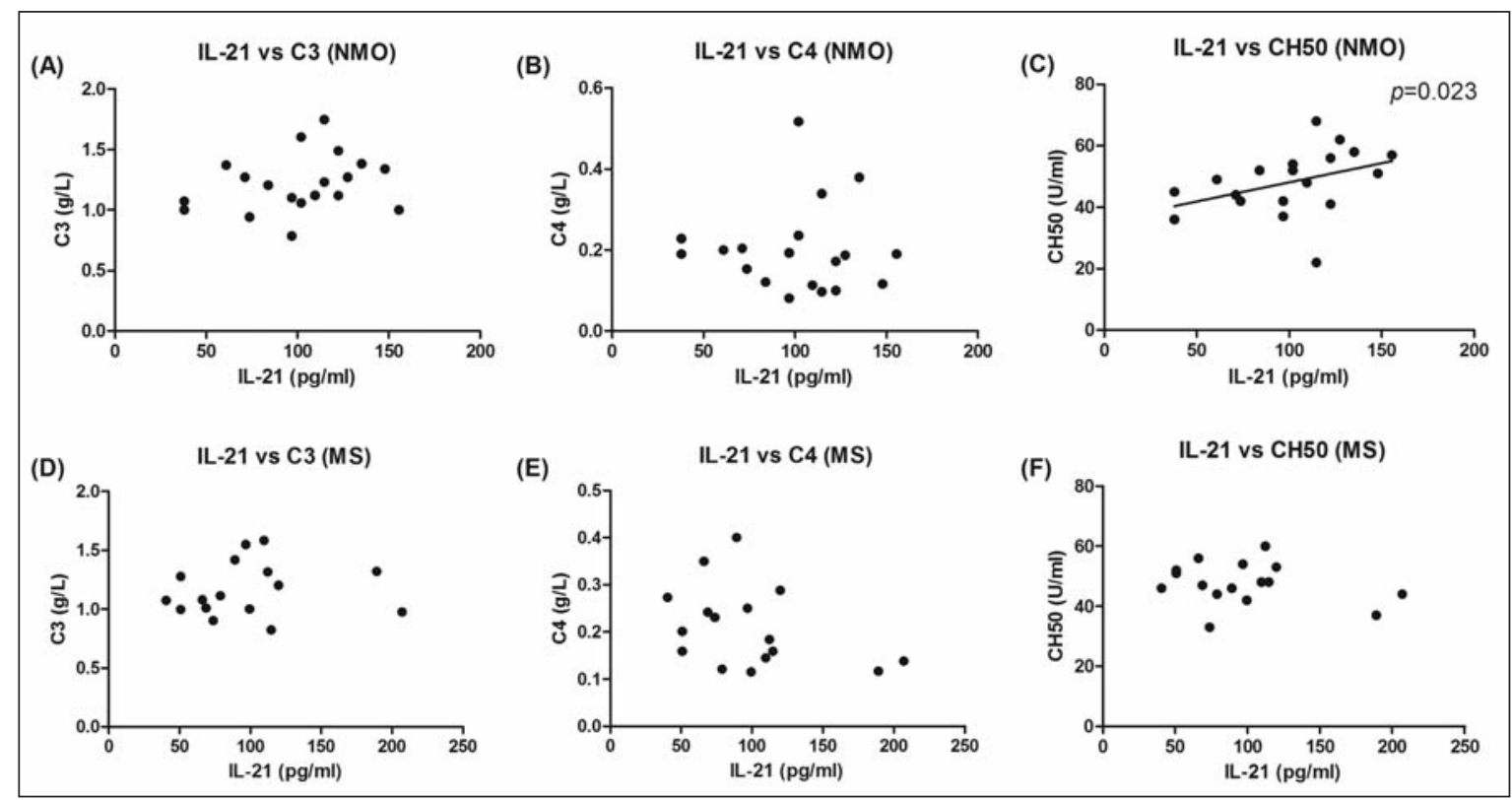

Figure 5: In NMO cohort, IL-21 concentration had a significantly positive correlation with CH5O ( $p=0.023)$. No correlation between CSF IL-21 and complement was found in MS cohort (C3, $p=0.676 ; C 4, p=0.122 ; C H 50, p=0.644)$. 


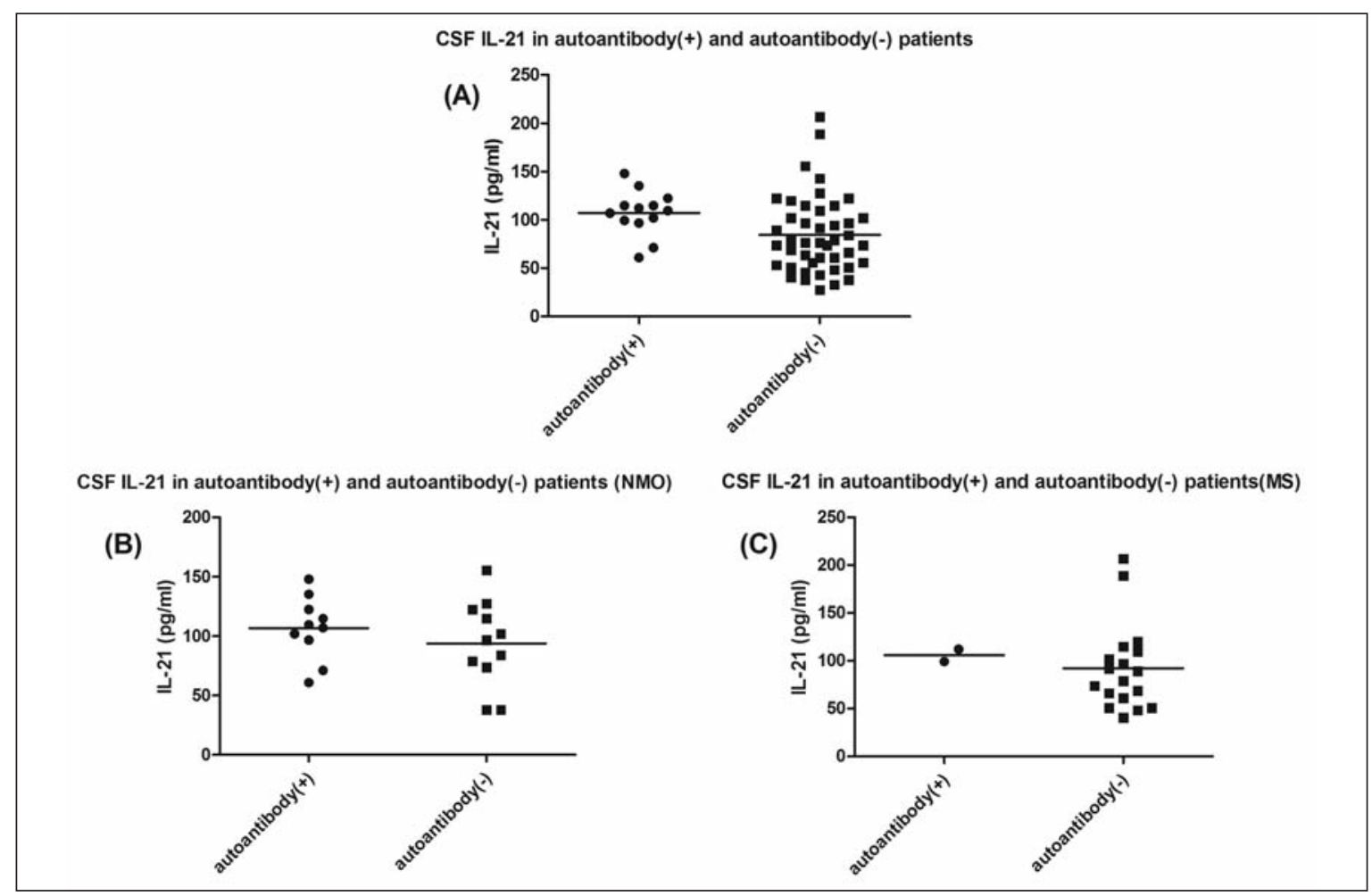

Figure 6: IL-21 level was much higher in the autoantibody-positive (autoantibody $(+))$ subgroup $(p=0.027)$. No significant difference between patients with autoantibody-positive and patients with autoantibody-negative (autoantibody(-)) was found when comparing IL-21 levels in both cohort (NMO, $p=0.438 ; M S, p=0.313$ ).

cohort and $43.88 \pm 11.18$ in controls. In NMO cohort, IL-21 concentration had a significantly positive correlation with $\mathrm{CH} 50$ $(p=0.023)$. While no correlation between CSF IL-21 and complement was found in MS cohort (C3, $p=0.676$; $\mathrm{C} 4$, $p=0.122 ; \mathrm{CH} 50, p=0.644)$. (Figure 5)

\section{CSF IL-21 and autoantibody}

Autoantibodies of all patients and controls were detected. Overall, autoantibodies to at least one autoantigen were found in 12 patients $(\mathrm{NMO}=10, \mathrm{MS}=2$, controls $=0)$. Mean IL-21 of autoantibody-positive (autoantibody(+)) subgroup was $103.99 \pm 23.46$ and the level was $89.10 \pm 41.30$ in autoantibodynegative (autoantibody(-)) subgroup. IL-21 level was much higher in the former subgroup $(\mathrm{p}=0.027)$. (Figure 6)

In NMO cohort, autoantibody(+) patients had a mean IL-21 of $106.76 \pm 26.48$, and autoantibody(-) patients had a mean of $93.75 \pm 36.42$. Mean IL-21 was $105.74 \pm 9.05$ in autoantibody(+) subgroup and 92.09 \pm 45.37 in autoantibody(-) subgroup in MS cohort. No significant difference between patients with autoantibody(+) and patients with autoantibody(-) was found when comparing IL-21 levels in both cohorts (NMO, $p=0.438$; MS, $\mathrm{p}=0.313$ ).

\section{Discussion}

In this case-control study, we revealed for the first time that CSF concentration of IL-21 was noticeably elevated in NMO and was borderline significantly increased in MS. In addition, this occurrence was associated with humoral immune activity as shown by a correlation between CSF IL-21 and complement in NMO cohort and high IL-21 level in autoantibody-positive subgroup.

Studies from several laboratories have convincingly shown the effect of IL-21 on promoting tissue damage in EAE. IL-21 administration before modeling was demonstrated to enhance severity of EAE, and autoreactive T cells purified from IL-21treated mice transferred more severe EAE than control encephalitogenic $\mathrm{T}$ cells ${ }^{25}$. These results indicated that an influence of IL-21 on immune regulatory circuit could be important in the modulation of the course of EAE. Therefore, IL21 may be a therapeutic target to protect tissue damage in inflammatory process. IFN- $\beta$, currently serving as one of the major treatments for MS, used in vitro significantly inhibited the production of $\mathrm{IL}-21$ in $\mathrm{CD}^{+} \mathrm{T}$ cells derived from PBMC. Administration of IFN- $\beta$ to EAE mice ameliorated the disease severity along with decreases in serum levels of IL- $21^{26}$. Other novel therapies, such as simvastatin ${ }^{27}$, curcumin ${ }^{28}$, DNA vaccine $^{29}$, also ameliorated EAE by down-regulating expression of IL-21. Taken together, the results from both in vitro and in vivo experiments suggested evaluating effects of IL-21 in human CNS autoimmune demyelinating disease. It has been reported that serum IL-21 levels were elevated in many autoimmune diseases, such as systemic lupus erythematosus, rheumatoid arthritis and Sjogren's syndrome ${ }^{30,31}$. Consistent with previous findings, we demonstrated a high level of serum IL-21 in NMO 
and $\mathrm{MS}^{22}$. However, the CSF concentration of IL-21 in NMO and MS patients remained to be investigated.

In the present study, CSF IL-21 levels in NMO, inwhich B cells were believed to play an important role in its pathogenesis, was significantly higher than MS and controls. Moreover, patients with higher relapse rates exhibited higher IL-21 concentration in their CSF in the NMO cohort. Since IL-21 is a pleiotropic cytokine and is recognized as "An Executor of B Cell Fate", these findings confirm the hypothesis that IL-21 has a decisive role in initiating and shaping pathologic responses in autoimmune diseases, especially the humoral immunity mediated by B cell immune response. It is plausible that more severe inflammation is involved in pathogenetic mechanisms of NMO, which corresponds well with more serious clinical symptoms and neurological disability of NMO compared to MS. In addition, IL-21 concentration had a significantly positive correlation with $\mathrm{CH} 50$ in the NMO cohort. The complement system is a humoral mechanism, which appears to play a particularly significant role in the development of $\mathrm{NMO}^{32,33}$, as both clinical and experimental studies have implicated NMO$\mathrm{IgG}$ inducing complement activation as a major pathogenic factor causing CNS destruction in $\mathrm{NMO}^{34,35}$. This phenomenon equally demonstrates that rising levels of IL-21 in NMO patients may promote disease activity by B cell immune response.

Another finding of our study was the high IL-21 level in the autoantibody-positive subgroup. Since the presence of autoantibody is associated with autoimmune humoral response, these data further support the role of IL-21 in humoral immune modulating.

In MS cohort, CSF IL-21 levels were slight elevated, and a trend of an increased IgG index with increased CSF IL-21 was observed. Though extensive work has been done, the role of IL21 in the pathogenesis of MS remains controversial. Genetic studies in Spain ${ }^{36}$ and Sweden ${ }^{37}$ showed no association between IL-21 and MS susceptibility and disease progression. However, these findings were challenged by a recent study. In this study, John and coworkers investigated IL-21/IL-21R expression in MS lesions by in situ hybridization and immunohistochemistry. They detected strongly IL- $21^{+}$infiltrating cells predominantly in acute but also in chronic active white matter MS lesions ${ }^{38}$. Therefore, additional studies using much larger sample sizes and more advanced technology will be required to ascertain contributions of IL-21 to MS pathogenesis.

In conclusion, our study revealed for the first time that the level of CSF IL-21 was elevated in NMO and might have a positive correlation with humoral immune activity. Further investigation on the precise role that IL-21 plays in CNS demyelinating diseases may provide insights in the pathogenesis and drug targets for the treatment.

\section{ACKNOWLEDGMENTS}

This study was supported by grants from the National Natural Science Foundation of China (No.81171126), grants from the Science and Technology Project of Guangzhou City (2008Z1E251) and Supported by the Ph.D. Programs Foundation of Ministry of Education of China (200805580084).

Aimin Wu, Xiaonan Zhong and Honghao Wang contributed equally to the manuscript.

\section{REFERENCES}

1. Matà S, Lolli F. Neuromyelitis optica: an update. J Neurol Sci. 2011;303(1-2):13-21.

2. Fletcher JM, Lalor SJ, Sweeney CM, et al. T cells in multiple sclerosis and experimental autoimmune encephalomyelitis. Clin Exp Immunol. 2010;162(1):1-11.

3. Li Y, Wang H, Long Y, et al. Increased memory Th17cells in patients with neuromyelitis optica and multiple sclerosis. J Neuroimmunol. 2011;234(1-2):155-60.

4. Link H, Tibbling G. Principles of albumin and IgG analyses in neurological disorders. III. Evaluation of IgG synthesis within the central nervous system in multiple sclerosis. Scand J Clin Lab Invest. 1977;37(5):397-401.

5. Archelos JJ, Storch MK, Hartung HP. The role of B cells and autoantibodies in multiple sclerosis. Ann Neurol. 2000;47(6): 694-706.

6. Lennon V.A, Wingerchuk DM, Kryzer TJ, et al. A serum autoantibody marker of neuromyelitis optica: distinction from multiple sclerosis. Lancet. 2004;364(9451):2106-12.

7. Watanabe S, Nakashima I, Misu T, et al. Therapeutic efficacy of plasma exchange in NMO-IgG-positive patients with neuromyelitis optica. Mult Scler. 2007;13(1):128-32.

8. Bakker J, Metz L. Devic's neuromyelitis optica treated with intravenous gamma globulin (IVIG). Can J Neurol Sci. 2004;31 (2):265-7.

9. Cree BA, Lamb S, Morgan K, et al. An open label study of the effects of rituximab in neuromyelitis optica. Neurology. 2005;64 (7):1270-2.

10. Bedi GS, Brown AD, Delgado SR, et al. Impact of rituximab on relapse rate and disability in neuromyelitis optica. Mult Scler. 2011;17(10):1225-30.

11. Pellkofer HL, Krumbholz M, Berthele A, et al. Long-term followup of patients with neuromyelitis optica after repeated therapy with rituximab. Neurology. 2011;76(15):1310-5.

12. Ozaki K, Kikly K, Michalovich D, et al. Cloning of a type I cytokine receptor most related to the IL-2 receptor beta chain. Proc Natl Acad Sci USA. 2000;97(21):11439-44.

13. Parrish-Novak J, Dillon SR, Nelson A, et al. Interleukin 21 and its receptor are involved in NK cell expansion and regulation of lymphocyte function. Nature. 2000;408(6808):57-63.

14. Spolski R, Leonard WJ. Interleukin-21: basic biology and implications for cancer and autoimmunity. Annu Rev Immunol. 2008:26:57-79.

15. Monteleone G, Caruso R, Fina D, et al. Control of matrix metalloproteinase production in human intestinal fibroblasts by interleukin 21. Gut. 2006;55(12):1774-80

16. Monteleone G, Pallone F, Macdonald TT. Interleukin-21 as a new therapeutic target for immune-mediated diseases. Trends Pharmacol Sci. 2009;30(8):441-7.

17. Deenick EK, Tangye SG. Autoimmunity: IL-21: a new player in Th17-cell differentiation. Immunol Cell Biol. 2007;85(7):503-5.

18. Monteleone G, Pallone F, Macdonald TT. Interleukin-21 (IL-21)mediated pathways in T cell-mediated disease. Cytokine Growth Factor Rev. 2009;20(2):185-91.

19. Konforte D, Simard N, Paige CJ. IL-21: an executor of B cell fate. J Immunol 2009;182(4):1781-7.

20. Ettinger R, Kuchen S, Lipsky PE. Interleukin 21 as a target of intervention in autoimmune disease. Ann Rheum Dis. 2008;67 Suppl 3:iii83-6.

21. Ettinger R, Kuchen S, Lipsky PE. The role of IL-21 inregulating Bcell functionin health and disease. Immunol Rev. 2008;223: 60-86.

22. Wang HH, Dai YQ, Qiu W, et al. Interleukin-17-secreting T cells in neuromyelitis optica and multiple sclerosis during relapse. J Clin Neurosci. 2011;18(10):1313-7.

23. Wingerchuk DM, Lennon VA, Pittock SJ, et al. Revised diagnostic criteria for neuromyelitis optica. Neurology. 2006;66(10): 1485-9.

24. Polman CH, Reingold SC, Banwell B, et al. Diagnostic criteria for multiple sclerosis: 2010 revisions to the McDonald criteria. Ann Neurol. 2011;69(2):292-302. 
25. Vollmer TL, Liu R, Price M, et al. Differential effects of IL-21 during initiation and progression of autoimmunity against neuroantigen. J Immunol. 2005;174(5):2696-701.

26. Chen M, Chen G, Nie H, et al. Regulatory effects of IFN-beta on production of osteopontin and IL-17 by CD4+ T Cells in MS. Eur J Immunol. 2009;39(9):2525-36.

27. Zhang X, Tao Y, Troiani L, et al. Simvastatin inhibits IFN regulatory factor 4 expression and Th17 cell differentiation in CD4+ T cells derived from patients with multiple sclerosis. J Immunol. 2011;187(6):3431-7.

28. Xie L, Li XK, Funeshima-Fuji N, et al. Amelioration of experimental autoimmune encephalomyelitis by curcumin treatment through inhibition of IL-17 production. Int Immunopharmacol. 2009;9(5):575-81.

29. Andersson A, Isaksson M, Wefer J, et al. Impaired autoimmune T helper 17 cell responses following DNA vaccination against rat experimental autoimmune encephalomyelitis. PLoS One. 2008;3(11):e3682.

30. Kwok SK, Cho ML, Park MK, et al. Interleukin-21 promotes osteoclasto genesis in rheumatoid arthritis in humans and mice. Arthritis Rheum. 2012;64(3):740-51

31. Kang KY, Kim HO, Kwok SK, et al. Impact of interleukin-21 in the pathogenesis of primary Sjogren's syndrome: increased serum levels of interleukin-21 and its expression in the labial salivary glands. Arthritis Res Ther. 2011;13(5):R179.
32. Tüzün E, Kürtüncü M, Türkoğlu R, et al. Enhanced complement consumption in neuromyelitis optica and Behçet's disease patients. J Neuroimmunol. 2011;233(1-2):211-5.

33. Doi $\mathrm{H}$, Matsushita $\mathrm{T}$, Isobe $\mathrm{N}$, et al. Hypercomplementemia at relapse in patients with anti-aquaporin-4 antibody. Mult Scler. 2009; 15(3):304-10.

34. Bradl M, Misu T, Takahashi T, et al. Neuromyelitis optica: pathogenicity of patient immunoglobulin in vivo. Ann Neurol. 2009;66(5):630-43.

35. Jarius S, Paul F, Franciotta D, et al. Mechanisms of disease: aquaporin-4 antibodies in neuromyelitis optica. Nat Clin Pract Neurol. 2008;4(4): 202-14.

36. Fedetz M, Ndagire D, Fernandez O, et al. Multiple sclerosis association study with the TENR-IL2-IL21 region in a Spanish population. Tissue Antigens. 2009;74(3):244-7.

37. Lindén M, Nohra R, Sundqvist E, et al. No evidence of IL21 association with multiple sclerosis in a Swedish population. Tissue Antigens. 2011;78(4):271-4.

38. Tzartos JS, Craner MJ, Friese MA, et al. IL-21 and IL-21 receptor expression in lymphocytes and neurons in multiple sclerosis brain. Am J Pathol. 2011;178(2):794-802. 